\title{
ATENDIMENTO DA POPULAÇÃO MASCULINA EM UNIDADE BÁSICA SAÚDE DA FAMÍLIA: MOTIVOS PARA A (NÃO) PROCURA
}

\author{
Health care for male population in basic unit of family health: reasons for (not) \\ attendance \\ Cuidado de la población masculina en unidad básica de salud de la familia: motivos \\ para la (no) búsqueda
}

Katiucia Letiele Duarte Vieira ${ }^{1}$

Vera Lúcia de Oliveira Gomes²

Marta Riegert Borba ${ }^{3}$

César Francisco da Silva Costa ${ }^{4}$

\section{RESUMO}

Estudo exploratório descritivo, que objetivou conhecer os motivos que levam homens a procurar atendimento de saúde e compreender os motivos que os afastam de uma Unidade Básica de Saúde da Família (UBSF) no sul do Brasil. Pela análise dos prontuários, identificaram-se 175 atendimentos a homens entre 25 e 59 anos em 2010. Problemas agudos acometeram 93 (52,2\%) usuários, a dor desencadeou 42 (23,6\%) dos problemas crônicos, hipertensão arterial acometeu 37 (21,4\%) clientes. Com entrevistas apreenderam-se os motivos de afastamento daquela UBSF. Sentiam-se saudáveis, por isso frequentavam pouco 0 serviço de saúde, ficando dez anos ou mais sem procurá-lo. Além de questões de gênero, alegaram incompatibilidade de horário, medo de detectarem doença grave, número insuficiente de fichas e falta de especialistas. Para atender às peculiaridades da população masculina, é necessário que os profissionais de saúde se capacitem, problematizem a realidade de cada UBSF e, juntamente com os gestores, vislumbrem e operacionalizem estratégias inclusivas de atendimento.

Palavras-chave: Enfermagem. Saúde do homem. Políticas públicas de saúde. Identidade de gênero.

\begin{abstract}
This exploratory and descriptive study aimed to know the reasons that lead men to seek healthy care and understand the reasons that depart them from the Basic Unit of Family Health in the southern tip of Brazil. For the analysis of the records, 175 attendances to men ranging from 25 to 59 years old in 2010 were identified. Acute problems were reported by 93 (52.2\%) users, the pain triggered $42(23.6 \%)$ of chronic problems, hypertension, struck $37(21.4 \%)$ clients. Through interviews it was possible to understand what moves them away from the Basic Unit of Family Health. Notably, men felt healthy, so little did they attend the health service, thus, it might take them ten years or more to look for it. In addition to gender issues, alleged scheduling conflict, fear to detect any serious disease, insufficient number of appointments and a lack of specialists. In order to accomplish the peculiarities of the male population it urges qualification on health professionals, so as to problematize the reality of each Basic Unit of Family Health and, along with managers, resolve and enable inclusive service.
\end{abstract}

keywords: Nursing. Men's Health. Public Health Policies, Gender Identity

\section{Resumen}

Este estudio tuvo como objetivo conocer las razones que conducen los hombres a buscar atención de salud y entender por qué se apartan de una Unidad Básica de Salud de la Familia (UBSF) en el sur de Brasil. Por el análisis de los registros fueron identificados 175 atendimientos prestados a hombres entre 25 y 59 años en 2010. Problemas agudos acometieran 93 (52,2\%) usuarios, el dolor desencadenó 42 (23,6\%) de los problemas crónicos, hipertensión arterial golpeó $37(21,4 \%)$ pacientes. Con las entrevistas se aprehendieron los motivos que los alejaban de aquella UBSF. Ellos se sentían sanos, por lo que asistían poco a los servicios de salud, permaneciendo diez años o más sin buscarlo. Además de las cuestiones de género, alegaron conflicto de programación, el miedo de detectar cualquier enfermedad grave, un número insuficiente de fichas y la falta de especialistas. Para hacer frente a las peculiaridades de la población masculina es necesario que los profesionales de salud se califiquen, cuestionen la realidad de cada UBSF y juntamente con gestores, vislumbren y realicen estrategias de inclusión de atención.

Palabras clave: Enfermería. Salud del Hombre. Políticas Públicas de la Salud. Identidad de Género.

\footnotetext{
${ }^{1}$ Enfermeira pela Escola de Enfermagem da Universidade Federal do Rio Grande. EEnf/FURG. Integrante do Grupo de Estudos e Pesquisas sobre Enfermagem Gênero e Sociedade. GEPEGS, Florianópolis-SC. Brasil. E-mail: katiletiele@yahoo.com.br; ${ }^{2}$ Enfermeira. Doutora em Enfermagem. Professora Titular da EEnf/FURG. Líder do GEPEGS. Tutora do Programa de Educação Tutorial PET/Enfermagem, FURG, Rio Grande- RS. Brasil. E-mail: vlogomes@terra.com.br; ${ }^{3}$ Enfermeira. Mestre em Enfermagem. Professora Adjunta da EEnf/FURG. Coordenadora Pedagógica da Residência Multiprofissional em Saúde da Família/FURG. Membro do PET/Enfermagem/FURG. Rio Grande-RS. Brasil. E-mail: mrborba@vetorial.net; ${ }^{4}$ Enfermeiro. Mestre em Enfermagem. Professor Assistente da EEnf/FURG. Integrante do Grupo de Estudos e Pesquisas Sobre Organização do Trabalho da Enfermagem e Saúde (GEPOTES). Rio Grande-RS. Brasil. E-mail: enf.cesar@ibest.com.br.
} 


\section{INTRODUÇÃO}

Inquéritos populacionais e estudos de avaliação de demanda têm apontado a baixa adesão da população masculina aos serviços de Atenção Básica de Saúde. Uma das prováveis consequências dessa conduta pode estar retratada em recentes indicadores de mortalidade, cujos resultados evidenciam que, em todas as faixas etárias e em decorrência de quase todas as causas, os homens morrem mais precocemente que as mulheres ${ }^{1-3}$.

A Atenção Básica de Saúde considera o ser humano em sua singularidade, complexidade, integralidade e inserção sociocultural, buscando promover a saúde, prevenir e tratar enfermidades, além de reduzir danos ou sofrimentos que possam comprometer suas possibilidades de um viver saudável ${ }^{4}$. Assim, o desejável seria que o acesso da população masculina aos serviços de saúde ocorresse de forma equitativa com os demais segmentos populacionais.

No entanto, inúmeras são as questões de gênero que dificultam ou mesmo impedem o acesso dos homens a esses serviços, entre elas cita-se a necessidade, culturalmente construída, de parecerem mais fortes que as mulheres e, consequentemente, não adoecerem e não necessitarem de cuidados. Além disso, os homens percebem as Unidades Básicas de Saúde (UBS) como espaços feminilizados, frequentados basicamente por mulheres, com equipes compostas fundamentalmente por profissionais do sexo feminino, que não desenvolvem programas direcionados especificamente a eles $^{3,5,6}$

Os agravos decorrentes dessa atitude constituem verdadeiros problemas de saúde pública, pois o acesso dos homens aos serviços de saúde vem ocorrendo por meio da assistência especializada. Essa "resistência masculina à atenção primária aumenta não somente a sobrecarga financeira da sociedade, mas também, e sobretudo, o sofrimento físico e emocional do paciente e de sua família, na luta pela conservação da saúde e da qualidade de vida":25.

Reconhecendo que a saúde é um direito social básico e de cidadania de todos os homens brasileiros, o Ministério da Saúde (MS) implantou, em 2008, a Política Nacional de Atenção Integral à Saúde do Homem (PNAISH)². Essa política foi estabelecida mediante um recorte estratégico, destinando-se a quase 40 milhões de homens na faixa etária de 25 a 59 anos. Este grupo etário correspondia, naquela ocasião, a $41,3 \%$ da população masculina ou a $20 \%$ do total da população brasileira, representando significativa parcela da força produtiva com importante papel no panorama sociocultural e político do Brasil'.

Para abranger essa parcela da população, o MS alinhou a PNAISH com a Política Nacional de Atenção Básica (PNAB), porta de entrada do Sistema Único de Saúde. Assim, procura promover ações que contribuam significativamente para a compreensão da singular realidade masculina nos contextos socioculturais e político-econômicos, possibilitando "o aumento da expectativa de vida e a redução dos índices de morbimortalidade por causas preveníveis e evitáveis nessa população":i: Sabe-se que os brasileiros têm maior dificuldade no que diz respeito ao autocuidado, e incluir a participação masculina em ações de saúde constitui um desafio. 0 cuidar de si ou de outros é uma questão intrínseca de gênero, ou seja, para o homem, o processo do cuidar diz respeito somente à mulher ${ }^{6,7}$. A não valorização do corpo para a promoção da saúde, associada ao fato de sentirem-se fortes, torna-os mais vulneráveis a doenças. Pesquisas evidenciam que, entre as principais causas de morbimortalidade masculina no Brasil, estão as doenças cardiovasculares, neoplasias malignas, doenças referentes à saúde mental, além de causas externas, como acidentes de trânsito, lesões autoprovocadas e agressões ${ }^{1,2,7-9}$. A PNAISH enfatiza que a modificação desse panorama requer mudança de paradigma e de atitudes.

Sabendo-se que a presença masculina nas UBS é baixa, optou-se por realizar o presente estudo com os objetivos de conhecer os motivos que levam os homens a procurar atendimento de saúde e compreender os motivos que os afastam do atendimento de saúde prestado em uma Unidade Básica de Saúde da Família (UBSF) situada no extremo sul do Brasil.

\section{METODOLOGIA}

Para cada objetivo, delineou-se um caminho metodológico específico. Assim, para conhecer os motivos que levaram os homens a procurar atendimento de saúde, realizouse um estudo descritivo, com abordagem quantitativa, por meio de pesquisa documental. Os dados foram collidos manualmente da totalidade de 984 prontuários das famílias registradas na Unidade Básica de Saúde da Família (UBSF) em estudo. Salientase que nessas famílias havia 639 homens na faixa etária de 25 a 59 anos. Na coleta, utilizou-se um formulário específico contendo questões referentes à idade, profissão e motivo do último atendimento do usuário. Como critério de inclusão, optouse que o registro deveria referir-se a atendimentos médicos ou de enfermagem, ocorridos entre janeiro e dezembro de 2010, para homens com idade entre 25 e 59 anos. 0 recorte temporal teve 0 intuito de captar dados recentes acerca do atendimento à população masculina, e o etário visou contemplar as diretrizes da PNAISH. Integraram essa amostra 175 atendimentos.

Para compreender os motivos que afastavam os homens da referida UBSF, realizou-se um estudo exploratório descritivo, com abordagem qualitativa. Adotou-se a entrevista semiestruturada como técnica de coleta de dados, sendo a seleção dos sujeitos efetuada por indicação das Agentes Comunitárias de Saúde (ACS). Todos foram informados acerca dos objetivos, da metodologia, bem como dos riscos e benefícios da pesquisa. Os que aceitaram participar do estudo assinaram, em duas vias, o Termo de Consentimento Livre e Esclarecido (TCLE). Nesse documento garantiu-se o sigilo das informações 
obtidas individualmente e a liberdade para se recusarem ou desistirem da pesquisa, em qualquer momento, sem que isso pudesse causar-lhes algum prejuízo. A coleta foi realizada em nível domiciliar pela pesquisadora.

0 roteiro das entrevistas contemplou questões relacionadas à presença de doenças, à sensação de ter alguma doença, à conduta adotada nessas situações, ao uso de medicamentos e à automedicação. No que se refere à procura pelos serviços de saúde, investigou-se a data e o motivo da última consulta bem como o serviço utilizado, se hospitalar ou UBS. Enfocando especificamente a UBSF do bairro, procurouse saber se o informante a conhecia, qual sua opinião acerca do atendimento prestado, motivos que o impediam de buscar 0 atendimento necessário e sugestões para sua melhoria. Finalmente se questionou a utilização de outro serviço de saúde e o porquê da preferência.

Para definir o número de entrevistas, adotou-se o critério de saturação dos dados, ou seja, as entrevistas só foram encerradas quando os acréscimos foram se tornando raros, até que deixaram de aparecer, o que ocorreu na décima entrevista. Mesmo assim, outras cinco foram realizadas confirmando-se a saturação ${ }^{10}$. Assim, foram realizadas 15 entrevistas. Os dados foram tratados por meio da análise de conteúdo na modalidade temática ${ }^{11}$. Para a identificação das falas, o código adotado foi a letra $\mathrm{H}$, seguida do número correspondente à idade do informante. Nas situações em que dois tinham a mesma idade utilizaram-se as letras a e $b$ para distingui-los. 0 projeto foi aprovado pelo Comitê de Ética em Pesquisa na Área da Saúde (CEPAS/FURG) sob o parecer n09/ 2011 e NEPES (Núcleo de Estudos e Pesquisas em Saúde) do município sob o parecer n 90-2/2010.

\section{RESULTADOS E DISCUSSÃO}

Os resultados deste estudo foram apresentados e discutidos em duas etapas. Na primeira, incluíram-se os motivos que levaram homens com idade entre 25 e 59 anos a procurar atendimento na UBSF estudada e, na segunda, os motivos que impediram ou dificultaram o acesso da população masculina à referida unidade.

\section{Motivos que levaram homens a procurar atendimento de saúde}

Entre os 175 usuários que procuraram por atendimento de saúde, durante 0 ano de 2010, identificou-se o predomínio da faixa etária de 45 e 54 anos, com 58 (33,2\%) homens, seguida das faixas etárias de 25 a 34 anos, com 43 (24,5\%) homens, e 35 a 44 anos, com 38 (21,7\%) homens. A menor procura à UBSF ocorreu com homens entre 55 a 59 anos com 36 (20,5\%) usuários.

Os dados apresentados aparentemente divergem de outros estudos, nos quais é preponderante a frequência de homens com idade mais elevada nos serviços de saúde, principalmente para o tratamento de doenças crônicas como diabetes e hipertensão ${ }^{3: 261}$. No entanto, cabe destacar que, entre os usuários com 55 a 59 anos, havia 15 hipertensos que realizavam aferição da pressão arterial com certa regularidade, mantendo elevada a frequência dessa população na UBSF estudada.

Analisando os motivos do atendimento, verificou-se que $93(52,2 \%)$ homens procuraram pelo serviço de saúde por problemas agudos, desses, a dor foi responsável por 42 (23,6\%) dos casos. Entre as doenças crônicas que motivaram a procura por atendimento, a Hipertensão Arterial foi a que mais acometeu os usuários, perfazendo um total de 37 (21,4\%) casos. Essa patologia foi registrada tanto de forma isolada, quanto associada a outros problemas como tabagismo e etilismo, demonstrando mais uma vez o descuido masculino com a própria saúde. Tais achados estão em consonância com os resultados de outras pesquisas que evidenciaram que a dor e patologias crônicas são os fatores que mais acometem a população masculina ${ }^{6,12}$. No ano de 2005, as alterações cardiovasculares foram responsáveis por $26,8 \%$ dos óbitos masculinos no Brasil2; nesse sentido, "há de se lamentar que perdemos anualmente muitas vidas e grande parte de nossa força produtiva em óbitos que poderiam ser perfeitamente evitados, se houvesse uma efetiva política de prevenção primária"::27

Vale salientar que a busca por esclarecimentos acerca da vasectomia foi o motivo de uma das consultas de enfermagem, não havendo outros registros de atendimentos para promoção de saúde ou prevenção de doenças. Nesse sentido, a bibliografia consultada aponta que, no imaginário masculino, a procura pelo "serviço de saúde, em uma perspectiva preventiva, poderia associá-lo à fraqueza, medo e insegurança; portanto, poderia aproximá-lo das representações do universo feminino, o que implicaria possivelmente desconfianças acerca dessa masculinidade socialmente instituída" ${ }^{" 5: 571 .}$.

\section{Motivos que impediram ou dificultaram o acesso da população masculina à UBSF}

Para compreender esses motivos, inicialmente delineouse o perfil dos entrevistados e, a seguir, os dados foram organizados em quatro categorias analíticas que incluíram: fatores que interferiram na percepção dos homens sobre seu estado de saúde; opinião dos homens acerca do atendimento prestado na UBSF; periodicidade com que procuraram atendimento de saúde; e, finalmente, os motivos que dificultaram ou impediram os homens de procurar o atendimento de saúde disponível na UBSF.

A idade dos 15 entrevistados oscilou entre 25 e 58 anos, nove tinham o Ensino Fundamental incompleto e cinco haviam completado essa fase de escolarização. Um informante referiu nunca ter frequentado escola, embora fosse alfabetizado. Enfocando especificamente 0 atendimento de saúde, 11 homens referiram utilizar somente o Sistema Único de Saúde (SUS) e quatro dispunham de convênios. As atividades profissionais 
exercidas pelos informantes eram muito diversificadas: microempresário, metalúrgico, funcionário de serviços gerais, chapeador, industriário, carpinteiro, pintor, torneiro mecânico, motorista, agricultor, um desempregado e três aposentados.

\section{Fatores que interferiram na percepção dos homens sobre seu estado de saúde}

Inúmeros são os estudos ${ }^{3,6,12}$ que discorrem sobre as barreiras existentes para que os homens usufruam dos serviços de saúde, alguns as problematizam culturalmente, pela associação entre masculinidade e a representação "de ser forte, ter corpo resistente e ser invulnerável” 12:908 Assim, a construção da masculinidade, regida através de marcas identitárias, tais como a invencibilidade, capacidade de exposição a riscos, status de dominador, ativo e provedor da família ${ }^{13}$, contribui para dificultar a adoção de ações promotoras de saúde, fazendo com que muitos homens se declarem saudáveis, mesmo sem conhecerem seu estado de saúde. Dez dos informantes, quando inquiridos sobre a existência de alguma doença, negaram essa condição. Desses, três reconheceram a possibilidade de uma patologia hereditária ou de vir a adoecer.

H58b- Por enquanto não!... Não!... Nunca examinei né...

H38- Não!... Que eu saiba não!... Mas tem... Como eu vou te dizer... Tem histórico de hipertensão e problemas cardiovasculares na família... Todo mundo morre do coração...

H27- Olha, que eu saiba não... Hereditária, sim. Tenho na família pessoas diabéticas... Minha mãe era hipertensa, mas não que eu saiba... Até consegui um fato inédito... De três anos pra cá minha glicose baixou [...] Eu troquei o açúcar pelo adoçante... Só e mais nada... Continuo tomando coca-cola todos os dias...

Raras são as situações em que o homem busca ajuda, $e$ isso geralmente ocorre por dois motivos: quando a dor se torna insuportável e quando há impossibilidade de trabalhar ${ }^{6}$. Em situações consideradas sem risco, a maioria dos homens lança mão de recursos alternativos, como usar alguma medicação por conta própria, procurar farmácias e chás caseiros. Tais alternativas, segundo eles, evitam a perda de tempo com filas e com a espera pelo atendimento médico. No presente estudo, nove dos sujeitos verbalizaram utilizar chás caseiros e automedicação, sendo o paracetamol, o ácido acetilsalicílico e relaxantes musculares os mais utilizados por indicação das esposas ou familiares.

H57b-É difícil eu me sentir doente... Não que eu seja o "super homem", mas eu não fico mesmo...
Olha eu costumo tomar remédio, né... um chá... [...] aí a gente toma uma comprimidinho vermelhinho, que eu não sei o nome. É pra dor... é barato e bom... Eu mesmo compro na farmácia... A minha esposa às vezes tem uma dorzinha e toma esse remédio, aíqualquer pessoa lá em casa tem uma dor e toma esse remédio [...] A esposa toma e o marido tem que tomar também...

Percebeu-se que a automedicação e a utilização de chás caseiros era muito comum entre eles, sendo uma construção cultural que vem sendo passada de geração em geração.

H35- Olha faz horas que eu não tomo... Quando tomo é uma coisinha ou outra... Um relaxante muscular, uma coisa assim pra dar uma descansadinha... Isso aí. [Questionado sobre quem indicou o entrevistado responde] Olha isso vem passando de geração pra geração... Se eu disser pra ti quem indicou... Foi a minha vó, depois veio minha mãe, meu pai... São coisinhas que a gente traz no "bolso" ou na "mala" da vida.

H58b- Às vezes... Tomo um comprimido, um remedinho caseiro... Um chá... De melissa... Isso já vem de família há muitos anos. Meu pai..., minha mãe...

Embora três homens tenham relatado que procuravam atendimento médico, quando doentes, enfatizaram que o faziam somente em situações extremadas confirmando a resistência da população masculina em se reconhecer com algum problema de saúde.

H40- 0 problema não é no posto... O problema é meu mesmo, não é que eu não goste de ir... Pra mim ir... só em último caso mesmo ...

H31-Só em casos extremos eu procuro o médico... Caso contrário, tomo um analgésico, alguma coisa... Ou nada mesmo... Dá e passa, mas é muito raro, não tenho por hábito tomar qualquer tipo de medicação.

H58a- Eu procuro um médico, mas eu não faço assim com muita frequência. [quando estou] com dor de garganta, eu tomo um chá caseiro, dor de cabeça eu não tenho muito.

À semelhança do descrito na bibliografia que fundamenta este estudo, a maior parte dos entrevistados se percebeu saudável e recorreu ao serviço de saúde apenas nas situações 
em que não conseguiu resolver seu problema com recursos alternativos.

\section{Opinião dos homens acerca do atendimento prestado na UBSF}

0 desconhecimento da maior parte dos homens acerca do atendimento prestado na UBSF do seu bairro ficou evidente. Dos entrevistados, cinco referiram não ter opinião, por não terem ido àquela unidade. Um deles tinha consciência da necessidade de controle de saúde, pois em sua família havia casos de doenças crônicas como diabetes e hipertensão. No entanto, à semelhança do que vem sendo apontado na literatura nacional e estrangeira, como ainda não havia enfrentado situações $\operatorname{críticas}^{13}$, mantinha a autopercepção de saudável e postergava a procura pelo atendimento. Questionados sobre o serviço de saúde prestado na UBSF de seu bairro responderam:

H27- Não seil Sei onde é, mas não conheço, nunca estive lá... Não tive o prazer de conhecer ainda... He! Hel Espero não precisar... Quando eu tiver longe de lá tá tudo bom!... He! He! Inclusive tenho que ir pra dar uma olhadinha na pressão e no açúcar...

H58b- Nesse posto eu nunca fui... Porque não foi preciso... He! He! He!"

Segundo a opinião dos dez informantes que conheciam o serviço, o atendimento prestado na UBSF era bom; no entanto, enfatizavam tê-lo conhecido ao acompanharem familiares com problemas de saúde.

H26- Pelo que eu sei é bom, já fui levar minha esposa... e as crianças...

H57b-Ah! Sim conheço, levo minha sogra lá... Acho que é bom não tenho nada para reclamar...

H57a- Eu não tenho nada a dizer... Nunca usei... Achei que não fosse preciso... He! He!... Eu já fui levar esse aqui (refere-se ao neto), ele colocou um brinco e infeccionou, aí eu levei ele para fazer curativo.

Os homens que procuraram atendimento para si não emitiram opinião acerca da qualidade do atendimento, apenas referiram conhecer o serviço e complementaram explicando as circunstâncias emergenciais em que o conheceram.

H54-Sim conheço, fiz um tratamento dentário no ano retrasado.

H 44-Eu já usei pra tomar uma injeção que eu tive que tomar... saiu uns furuncos aqui, aí eu tive que ir ali, elas me deram Benzetacil... E pra o controle antitetânico, a vacina só pra isso.

H58a- Em 2005, quando eu me queimei foi que eu usei o serviço para fazer curativo. Consultar eu não consultei nenhuma vez...

Assim, a frequência dos homens na UBSF parece ser baixa, motivo pelo qual a opinião acerca do atendimento prestado é restrita.

\section{Periodicidade com que os homens procuram atendimento de saúde}

Analisando o tempo decorrido da última consulta, percebeu-se que apenas procuravam o serviço médico com regularidade os homens com histórico de patologias crônicas, como um usuário com sequela oftalmológica de toxoplasmose e um com problemas neurológicos.

Quatro informantes realizaram sua última consulta entre um e cinco anos atrás; seus depoimentos permitiram perceber que a procura pelo atendimento ocorreu em situação de crise.

H57a- Já faz dois anos, foi por nervo ciático [...] eu forcei demais, eu trabalhava de pedreiro, aí eu estava sentindo o nervo ciático, eu comecei a forçar, forçar, aí foi quando não deu mais... A coisa piorou mesmo...

H38 A última vez... Faz... Em torno de cinco anos atrás, foi por princípio de infarto, mas é muito raro, nessa época eu estava com o nível de estresse muito alto... E aí o... negócio estourou...

Por outro lado, quando algum usuário foge à regra e solicita um check-up em decorrência de pequeno "mal-estar", os(as) próprios(as) profissionais o desestimulam, reproduzindo o polarizado imaginário que associa o feminino ao cuidado à saúde e o masculino ao não cuidado ${ }^{3,6}$. Tal atitude confirma a invisibilidade da figura masculina nos serviços, pela própria expectativa dos(as) profissionais, que "deixam de estimulá-los às práticas de promoção e prevenção da saúde ou não reconhecem casos em que eles demonstram tais comportamentos" ${ }^{\prime 3: 266}$.

H58a- Faz já uns três anos, eu pedi para fazer um check-up, andava sentindo um cansaço assim... Mas era mais estresse do serviço mesmo, olha faz uns dois ou três anos. Até o médico estranhou, perguntou o que eu estava sentindo, por que normalmente um exame de sangue não se pede toda hora. Uma vez por ano tá bom! Eu disse que 
já faz alguns anos que não faço. Ele disse que não se pede toda hora, mas... Tudo bem vamos fazer...

Houve ainda informantes cuja última consulta havia ocorrido há mais de dez anos ou que nem sabiam informar com precisão. Esses homens se percebiam saudáveis, seus problemas de saúde eram minimizados e tratados por conta própria.

H26-Bah!... Não me lembro... Olha vai fazer... Acho uns 10 anos... A única coisa que eu tenho de mais grave é gripe... E assim mesmo faz horas que eu não tenho gripe... Dor de dente, aí eu tomo um remédio... Vou na farmácia, compro remédio e tomo... Faz uns 10 anos que não vou no hospital procurar médico... Eu me sinto bem... Não vou procurar doença... Não estou doente..."

H58b- Não lembro!... Faz tanto tempo... Estava com o pé infeccionado por causa de um bicho de pé, fui no pronto-socorro e fiz uma injeção e vim pra casa.

H35-Bah! Nem me lembro... Eu era pequeno... Não me lembro... Nem sei o porquê... Nunca fui.

Cabe enfatizar que o fato de os usuários ficarem dez ou mais anos sem procurarem os serviços de saúde não representa desinformação. Há sim um descompasso entre o comportamento masculino e o conhecimento acerca das medidas para promoção de saúde e prevenção de doenças.

No que se refere ao câncer de próstata, por ser uma neoplasia de evolução muito lenta, a mortalidade pode ser evitada se o processo for diagnosticado e tratado precocemente 2 . Os meios de comunicação de massa advertem para a gravidade e a alta incidência dessa doença, ressaltando a importância da prevenção. Dessa forma, muitos homens reconhecem a necessidade da adoção de medidas preventivas, mas não as põem em prática.

H57b- Puxa faz tempo... Uns 10 anos, nunca mais fui ao médico... Só quando é pra levar alguém... Eu até tinha que fazer exame de próstata. Estou bem! Não sinto nada, mas sei que tenho que fazer.

Conforme preconiza o Ministério do Trabalho, no Programa de Controle Médico de Saúde Ocupacional, os trabalhadores menores de 18 anos e maiores de 45 anos devem realizar, anualmente, exames de rotina, e trabalhadores de 18 a 45 anos, a cada dois anos ${ }^{14}$. Dos integrantes deste estudo, apenas dois, por exigência da empresa em que trabalhavam, faziam esses exames. Isso demonstra que a promoção da saúde não constituía sua prioridade.

\section{Motivos que dificultam ou impedem os homens de procurar atendimento}

Diversos são os motivos pelos quais os homens não procuraram os serviços de saúde, entre eles figuram a demora no atendimento, vergonha pela exposição do corpo aos profissionais, medo da descoberta de uma doença grave, estereótipos de gênero que dificultam o autocuidado, além de não se reconhecerem alvo do atendimento ${ }^{2,6}$. Tais motivos emergiram entre os achados deste estudo. Quando questionados acerca do que os impedia de procurar a UBSF de seu bairro, doze sujeitos referiram não necessitarem de atendimento, pois se consideravam saudáveis, alguns deles disseram que preferiam deixar 0 atendimento para os mais necessitados.

H26-Acho que nenhum... Eu não vou ali por que... Fazer o quê... Até ia marcar uma consulta pra arrancar um dente, mas até agora não fui... Se precisar eu vou ali...

H57b- 0 que me impede de ir ali é que eu não sinto nada, eu estou bem... Não tenho tontura, não tenho problema de pressão, não tenho nada. Até, inclusive, lá perto de casa tem uma pessoa que trabalha na farmácia e foi lá tirar pressão da minha sogra e da minha esposa e já tirou a minha. estava bem, tudo bem.

Um informante mencionou a incompatibilidade do horário de atendimento da UBSF com sua jornada de trabalho. Estudos vêm evidenciando que nos serviços onde foram disponibilizados atendimento no horário do almoço, atendimento 24 horas, nos sábados e domingos, ou que criaram um terceiro turno à noite, houve maior presença masculina nos novos horários instituídos ${ }^{3,6}$. Isso reforça a necessidade de discussão acerca do acesso dos homens ao atendimento público de saúde.

H35- Uma pessoa como eu nem tem tempo de procurar um posto. Por que se tu vai no posto, tu ganha falta no serviço. Aí também ... Sábado e domingo tu não vai ali, tu não procura. Tá fechado...

0 temor de encontrar uma doença grave ao procurar o serviço de saúde, na ausência de sinais ou sintomas que evidenciem algum problema, foi expresso por um dos informantes. 0 Ministério da Saúde destaca que a descoberta de "que algo vai mal com a sua saúde põe em risco sua crença de invulnerabilidade"2:3. 
H40- Ela sabe... (refere-se à esposa) não é o serviço, é assim... O que tu procura tu vai achar... Penso eu assim... O que tu procura tu vai achar... Se eu pegar um caminhão que está bom ali... Ele está bom, eu coloco ele na oficina e vai aparecer mil defeitos. Eu penso que com a saúde é a mesma coisa. Eu não tenho nada, mas de repente eu vou ali fazer um exame disso ou daquilo e vai aparecer isso ou aquilo, principalmente coisa que eu não tenho... Então o meu pensar é assim... Quem procura acha... Posso estar errado né? Mas...

A falta de atendimento por parte de especialistas também foi verbalizada. No entanto, para exemplificar essa limitação, o informante citou a falta de ginecologistas e pediatras na UBSF, demonstrado mais uma vez que a necessidade não é sua, mas sim dos(as) outros(as). Por outro lado, a carência de programas destinados à população masculina é uma realidade em nosso país, exceção se faz à saúde do trabalhador ${ }^{14}$.

Finalmente, os informantes foram questionados sobre as mudanças necessárias para aumentar a adesão masculina ao atendimento de saúde naquela UBSF. As opiniões centraram-se no tempo gasto e no número de fichas, com seis reclamações referentes ao pequeno número de fichas e à demora no atendimento:

H57a Olha, se tivesse mais médico ali seria melhor, porque uma vez eu fui tentar tirar uma ficha. Eu fui às sete horas da manhã... e depois às oito horas não tinha mais ficha, parece que eram cinco fichas só... Eu vim me embora e não fui mais [...] Não fui mais, não procurei mais... [Deveria ter mais médico?] É... Maior número de fichas... Épor causa da demora, eu vejo o pessoal se queixar né, vão hoje, vão amanhã, depois... Enão conseguem ficha, pra tirar uma ficha tem que ir bastante cedo...

\section{H57b O que eu acho ali... E não só ali, em tudo o que élugar, éa demora... A gente vai cedo pra láe sai dali quase meio dia... Esse é o problema, a gente perde muito tempo... O pessoal madruga pra tirar ficha... Aí, sai de lá meio dia... Não sei pra que a demora... Nem é tantas pessoas pra atender assim...}

Reclamações semelhantes foram detectadas em outros estudos e na própria política de atendimento à população masculina ${ }^{2}$. Assim, torna-se indispensável o delineamento de novas estratégias para o atendimento pleno das peculiaridades da população masculina, pois a falta de adesão aos serviços de saúde não pode ser associada apenas a questões de gênero.

\section{CONSIDERAÇÕES FINAIS}

As análises empreendidas neste estudo demonstram que os homens na faixa etária produtiva pouco procuram a UBSF. Dentre os fatores identificados figuram a falta de preocupação com ações voltadas à promoção da saúde e prevenção de doenças, a dificuldade em se reconhecerem doentes e o medo da descoberta de alguma doença grave.

Alem disso, estereótipos de gênero contribuem para o afastamento da população masculina das UBSF. Nesse sentido, tanto a população masculina precisa mudar sua percepção em relação ao cuidado com a própria saúde, quanto os(as) integrantes da equipe de saúde precisam adotar uma atitude de acolhimento aos homens que procuram os serviços. Todavia, garantir um acolhimento e atendimento equânime com os demais segmentos populacionais não significa tratar a todos(as) de forma idêntica, pois "as pessoas não são iguais e, por isso, têm necessidades distintas"15:501.

Assim, para o atendimento da população masculina, é necessário que os profissionais de saúde se capacitem, problematizem a realidade de cada UBSF e, juntamente com os gestores de saúde, vislumbrem e operacionalizem estratégias inclusivas para o público masculino, entre elas horários alternativos e implementação de programas específicos. 0 repensar das questões que permeiam a saúde do homem e a mudança de atitude profissional podem desencadear nessa população a sensação de pertencimento ao espaço de promoção, proteção e recuperação de saúde.

\section{REFERÊNCIAS}

1.Laurenti R, Mello-Jorge MHP, Gotlieb SLD. Perfil epidemiológico da morbimortalidade masculina. Ciênc. saúde coletiva [online]. 2005 jan/mar; [citado 2010 dez. 15]; 10(1): [aprox.12 telas]. Disponível em http://uww.scielo.br/ scielo.php?script=sci_arttext\&pid=S1413-81232005000100010.

2.Ministério da Saúde (BR), Secretaria de atenção à Saúde, Departamento de Ações Programáticas Estratégicas. Política Nacional de Atenção Integral à Saúde do Homem: princípios e diretrizes [citado 2010 nov 20]. Brasília (DF): [Ministério da Saúde]; 2008.

3.Couto MT et al. 0 homem na Atenção Primária à saúde:discutindo a (in)visibilidade a partir da perspectiva de gênero. Interface comun. saúde educ.[online]. 2010 mar; [citado $2010 \mathrm{dez}$ 10]; 14(33): [aprox.13 telas]. Disponível em http://www.scielo.br/scielo.php?pid=S1414$32832010000200003 \&$ script $=$ sci_arttext. 
4.Ministério da Saúde (BR). Política Nacional de Atenção Básica a Saúde [on line]. 2006 maio; [citado $2010 \mathrm{dez}$ 09]; 2(1): [aprox.10 telas]. Disponível em http://www.conass.org.br/admin/arquivos/NT\%201206.pdf.

5.Figueiredo W. Assistência à saúde dos homens: um desafio para os serviços de atenção primária. Ciênc. saúde coletiva [online]. 2005 jan/mar; [citado 2010 dez 13]; 10(1): [aprox.5 telas]. Disponível em http://www.scielo.br/ scielo.php?pid $=$ S1413-81232005000100017\&script $=$ sci $\_$abstract\&tlng $=$pt.

6.Gomes R, Nascimento EF, Araújo FC. Por que os homens buscam menos os serviços de saúde do que as mulheres? As explicações de homens com baixa escolaridade e homens com ensino superior. Cad. saúde pública [on line]. 2007 mar; [citado 2010 dez 19]; 23(3): [aprox.10 telas]. Disponivel em http://www.scielo.br/pdf/csp/v23n3/15.pdf.

7.Pinheiro RS et al. Gênero, morbidade, acesso e utilização de serviços de saúde no Brasil. Ciênc. saúde coletiva [online]. 2002 nov/dez; [citado 2010 dez 19]; 7(4): [aprox.20 telas]. Disponível em http://www.scielo.br/ pdf/csc/v7n4/14599.pdf.

8.Braz M. A construção da subjetividade masculina e seu impacto sobre a saúde do homem: reflexão bioética sobre justiça distributiva. Ciênc. saúde coletiva [online].2005 jan/mar; [citado 2010 dez 13]; 10(1): [aprox. 8telas]. Disponível em http://www.scielo.br/pdf/csc/v10n1/a10v10n1.pdf.

9.Souza ER. Masculinidade e violência no Brasil: contribuições para a reflexão no campo da saúde. Ciênc. saúde coletiva [online]. 2005 jan/ mar; [citado 2010 dez 11]; 10(1): [aprox. 11 telas]. Disponível em http:/ / www.scielo.br/scielo.php?pid=S1413-81232005000100012\& script=sci_arttext.

10.Fontanella BJB, Ricas JA Turato ER. Amostragem por saturação em pesquisas qualitativas em saúde: contribuições teóricas. Cad. saúde pública [on line]. 2008 jan; [citado 2009 dez 15]; 24(1): 17-27. Disponível em http://www.scielo.br/pdf/csp/v24n1/02.pdf.

11.Minayo MCS. 0 desafio do conhecimento: pesquisa qualitativa em Saúde. 10ª Ed. São Paulo (SP): Hucitec; 2009.

12.Gomes R, Nascimento EF. A produção do conhecimento da saúde pública sobre a relação homem-saúde: uma revisão bibliográfica. Cad. saúde pública [on line]. 2006 maio; [citado 2010 dez 15]; 22(5): [aprox.11 telas]. Disponível em http://www.scielo.br/pdf/csp/v22n5/03.pdf.

13.Nascimento EF, Gomes R. Marcas identitárias masculinas e a saúde de homens jovens. Cad. saúde pública [on line]. 2008 jul; [citado em 2010 dez 13]; 24(7): [aprox.9 telas]. Disponível em: http://www.scielo.br/pdf/ csp/v24n7/10.pdf.

14.Ministério do Trabalho (BR). NR 7 - programa de controle médico de saúde ocupacional. [on line]. 1996 out; [citado 2011 jun 16]: [aprox.12 telas]. Disponível em http://portal.mte.gov.br/legislacao/normasregulamentadoras-1.htm.

15.Pontes APM, Cesso RGD, Oliveira DC, Gomes AM. 0 princípio de universalidade do acesso aos serviços de saúde: o que pensam os usuários? Esc. Anna Nery. [online]. 2009 set; [citado 2011 Jun 3]; 13(3): [aprox. 8 telas]. Disponível em: http://www.scielo.br/pdf/ean/v13n3/ v13n3a07. 